\title{
Study of Different Gray Scale and Colour Doppler Ultrasonographic Findings for Diagnosis of Placenta Accreta
}

\author{
Tala Abo Elnasr*, Shereef Lotfy, Sameh Khodair and Karam Shaheen \\ Deparatment of Obstetrics and Gynecology, Faculty of Medicine Tanta University, Egypt \\ *Corresponding author
}

\section{A B S T R A C T}

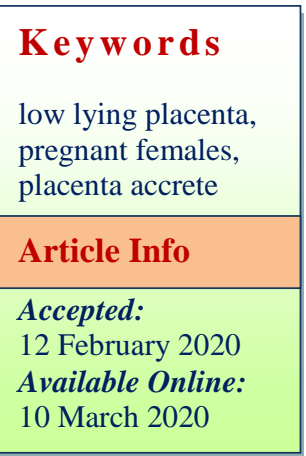

To optimize ultrasound and doppler signs for diagnosis of placenta accrete. prospective observational study. The method is to observe 30 pregnant females who had anterior low lying placenta or placenta previa with previous cesarean section were examined by ultrasound and Doppler at 20-24 wks and followed up every four weeks till termination of pregnancy by cesarean section for gray scale and colour Doppler signs of placenta accrete. The study resulted in " loss of retroplacental clear space" sign was found in 28 patients $(93.33 \%)$ at 28 weeks of gestation and in all patients (100\%) at 32 and 36 wks of gestation. Also in Doppler signs,"placental lacunae" sign was found in 28 cases $(93.33 \%)$ at 32 wks and 30 cases $(100.00 \%)$ at 36 wks of gestation. However "dilated vessels around the cervix" sign, only 2 cases $(6.67 \%)$ was found at 36 wks of gestation. It is concluded that the signs of diagnosis of placenta accreta by normal ultrasound and Doppler are sensitive and specific at different gestational ages, so early use of gray scale ultrasound and doppler is important in early diagnosis of placenta accreta.

\section{Introduction}

Placental adhesive disorder is a catastrophic and life-threatening obstetric condition which is an important cause of intrapartum and postpartum hemorrhage and peripartum hysterectomy. ${ }^{1}$ Placenta accrete (a collective term for accreta, increta and percreta) occurs as a result of a defect in the decidua basalis, allowing the anchoring villi to penetrate into the myometrium. ${ }^{2}$
The risk factors for placental adhesive disorder are: placenta previa, prior uterine surgery such as cesarean section, myomectomy, Asherman syndrome, endometrial defects due to vigorous curettage, corneal resection, anterior placenta, smoking, hypertension, pregnancy induced via in vitro fertilization (IVF), subserosal and submucosal myoma, and may vary while fetus is male or female. ${ }^{3}$ Most important complication of placenta accrete is due to catastrophic blood loss, other complications are adult respiratory 
distress syndrome, Sheehan's syndrome, renal failure, and even death. Thus there is a need for early reliable antenatal diagnosis of placenta accrete, if these pregnancies can be identified before delivery, the site and time of delivery, as well as the surgical approach, can be planned ahead and blood loss minimized. ${ }^{4}$

Diagnosis of placenta accreta could be done by gray-scale sonographic diagnostic criteria which include thinning of the myometrium underneath the placenta, Loss of the retroplacental "clear space and interruption of baldder line. ${ }^{5}$ while by using color Doppler includes diffuse and focal irregularly shaped placental lacunae, turbulent flow, tornado sign, increased peri-uterine vascularity between uterus and urinary bladder, interphase hypervascularity with abnormal blood vessels linking the placenta to the bladder and markedly dilated peripheral subplacental vascular channels with pulsatile venous-type flow over the uterine cervix. ${ }^{6}$

Operative management of placenta accrete was a matter of debate, and it ranges from hysterectomy with placenta insitu, to cutting the cord short without attemping removal of the placenta with post operative methotraxate intake and now there is wide varities of operative conservative treatment of placenta accrete either hemostatic suturing of placental bed, stepwise uterus preserving technique, trimming of lower uterine segment and bilateral uterine artery ligation ${ }^{7}$ With the sensitivity of individual criteria ranging from $7 \%$ to $93 \% .^{8}$ with the use of color and/or power Doppler, the reported sensitivity and specificity of antenatal diagnosis increase to 82.4-100\% and 92-96.8\%, respectively. ${ }^{9}$

\section{Cases selection}

This study had been conducted on 30 pregnant women attending the outpatient clinic and inpatient Department of Obstetrics and Gynecology, Tanta university hospital

They were selected according to the following criteria :

Gestational age of pregnancy 20-24 weeks

All patients had:

anterior low lying placenta in primigravida or anterior placenta previa with history of previous Cesarean section

They were excluded if :

Patients had moderate or severe antepartum hemorrhage.

Chronic diseases as any cardiac disease, renal and hepatic disease.

\section{Materials and Methods}

Written consent was taken from all patients submitted to the study withclarification of the methods, value and hazards of the study.

Detailed history taking from all patients.

Full general, systemic and pelvic examination.

Abdominal and transvaginal U/S examination with Doppler study:

It was done to the female at 20-24 weeks gestation Using Siemens Acuson X300 premium edition ultrasound. Ultrasound was done by ultrasound machines using the curvilinear transducer (at frequency 3-5 MHz) or endovaginal transducer (at frequency 3-9 $\mathrm{MHz}$ ). The lower uterine segment is evaluated using the highest-frequency transducer that can produce an adequate image, which is often a 5-MHz transducer. Transabdominal imaging is performed with the patient's bladder full. Transvaginal US is always performed when the placenta is low lying or placenta previa is present. 
The placenta was assessed for the following:

The gray-scale sonographic diagnostic criteria are:

Thinning of the myometrium underneath the placenta

Loss of the retroplacental "clear space,"

Protrusion of the placenta and may reach to the serosa of the bladder, (interruption of baldder line). ${ }^{6}$

Signs of placenta accrete by color Doppler study:

Diffuse irregularly shaped placental lacunae (vascular spaces) within the placenta,

Focal irregularly shaped placental lacunae (vascular spaces) within the placenta

Turbulent flow, tornado sign

Increased peri-uterine vascularity between uterus and urinary bladder,interphase hypervascularity with abnor mal blood vessels linking the placenta to the bladder

Markedly dilated peripheral subplacental vascular channels with pulsatile venous-type flow over the uterine cervix. $^{7}$

The patients have been followed up at 4 weeks interval till 36 weeks -38 weeks gestation (time of termination of pregnancy)

All patients at time of follow up visit have been checked for the maternal and fetal status, and checked for new complaint.

Follow up gray scale and Doppler ultrasound examination have been done and compare the findings with the previous findings for the appearance of new finding, disappearance of previous finding, progression of previous finding or the observation of no changes

All this data have been recorded in special file for the patients included in that study.

\section{Cesarean section}

Cesarean section has been done at $36-38$ weeks gestations according to maternal and fetal condition

Intraoperative observation of the degree of placental adhesion

Operative complications as bladder injury, atony or blood transfusion and postpartum complications as shock, sepsis or second operation if presented was recorded

All this data have been recorded in special file for the patients included in that study

Operative data have been correlated with the sonographic findings.

\section{Ethical approval}

This study was approved by local ethical committee of Tanta University before the start of this study.

\section{Results and Discussion}

In this study, it was found that " loss of retroplacental clear space" sign was found in all patients $(100 \%)$ at 32 and $36 \mathrm{wks}$ of gestation. And "placental lacunae" sign was found in all 30 cases $(100.00 \%)$ at $36 \mathrm{wks}$ of gestation. However "dilated vessels around the cervix" sign, only 2 cases $(6.67 \%)$ was found at 36 wks of gestation.

Degree of placenta accreta at time of operation was, $22(73.33 \%)$ cases had placenta accrete [3 patients (10\%) were accrete, 14 patients $(46.67 \%)$ were increta and 5 patients $(16.67 \%)$ were percreta] and 8 women were not accrete and placenta separated easly.fig (1)

Operative end results were $4(13.33 \%)$ cases underwent hysterectomy and $26(86.67 \%)$ women including the 8 women who were not accrete were completed conservative. (table 1). Complications were divided into; need for blood transfusion in 16 cases $(53.33 \%)$, bladder injury in 6 cases with $(20.00 \%)$ percentage and need ICU admission in 7 cases 
(23.33\%). Myometrial thining as a sign for placenta accreta was most accurate at 36 weeks of gestation with percentage of $83.33 \%$ and its sensitivity reaches to be $100 \%$ at 36 weeks of gestation and was most specific at 24 wks of gestation by percentage (100\%) (table 2).

Loss of retroplacental clear space was most specific at $20 \mathrm{wks}$ gestational age $(100 \%)$, was most accurate at 24 weeks of gestation by percentage of $83.33 \%$ and its sensitivity reaches $100 \%$ at 28,32 and 36 wks of gestation.(table 2)

Interruption of bladder line, it was specific at $32 \mathrm{wks}$ and $36 \mathrm{wks}$ of gestation by $100 \%$ despite that high specificity, its sensitivity was very low $22.73 \%$ at 36 weeks gestation, and so the accuracy was low at 36 wks by $43.33 \%$. This sign did not appear except after 32 weeks gestation.(table 2)

About placental lacunae, it shows $100 \%$ specificity at 20 and 24 wks of gestation and $100 \%$ sensitivity at $36 \mathrm{wks}$ of gestation then at 32 wks by $95 \%$ and more accurate at 28 wks by $80 \%$.(table 2 )

The tornado sign was $100 \%$ specific at 24,28 and 32 wks of gestation, it was $91 \%$ sensitive at 36 wks of gestation and most accurate with $86.67 \%$ at 36 wks of gestation (table 2).

increased periuterine vascularity between uterus and urinary bladder was $100 \%$ specific at 28,32,36 wks of gestation but shows low sensitivity with accuracy $60 \%$ at $36 \mathrm{wks}$.(table 2). Dilated vessels over the cervix didn't appear except at $36 \mathrm{wks}$ of gestation and with specificity $100 \%$, sensitivity was very low, and accuracy was $33 \%$.(table 2 )

It is desirable to identify placenta accreta before birth so plans can be made for a controlled delivery, available blood products, and back up surgical help to prevent forceful detachment of placenta from uterine wall and thus severe uncontobable hemorrhage that lead to hysterecyomy. ${ }^{10}$

Hemorrhagic and surgical complications associated with placental adhesive disorder depend on the depth of placental invasion and involvement of adjacent structures. ${ }^{11}$

Placenta adhesive disorder with bladder invasion is a serious condition, which necessitates proper antenatal diagnosis and appropriate management strategy 10

The risk of performing an unnecessary hysterectomy (false positive) or the risk of secondary bleeding following attempted placental removal (false negative) should always be considered.

This study was conducted on 30 pregnant women attended the outpatient clinic and inpatient Department of Obstetrics and Gynecology, Tanta university hospital. The study was taken from December 2017 to December 2018

For all selected patients, they were followed till 36-38 weeks of gestation by First Abdominal U/S examination and colour Doppler to optimize ultrasound and doppler signs for diagnosis of placenta accrete. After proper statistical analysis it was found that All of the 22 cases having placenta accreta, $(100 \%)$ had placental lacunae with Doppler abnormality. Placental lacunae were found in all women with placenta accreta with specificity at 20 wks and 24 wks of gestation by $100 \%$ and sensitivity at 36 wks of gestation by $100 \%$ but at 32 wks by $95.45 \%$.

According to thinning of the myometrium underneath the placenta, in our study we found that it was most accurate at 36 weeks 
of gestation with percentage of $83.33 \%$ and its sensitivity reaches to be $100 \%$ at 36 weeks of gestation and was most specific at 24 wks of gestation by percentage $(100 \%)$. These results were in agreement with Shawky et al., study ${ }^{12}$ ( in their study on 50 pregnant women, 18 of the 50 pregnant woman were diagnosed as placenta accreta by surgical criteria on doing Cesarean section )and Wong et al., study in specifity of $100 \%$ but in disagreement with sensitivity. ${ }^{13}$

According to loss of retroplacental clear space, in our study we found that it was most specific at $20 \mathrm{wks}$ gestational age $(100 \%)$, was most accurate at 24 weeks of gestation by percentage of $83.33 \%$ and its sensitivity reaches $100 \%$ at 28,32 and 36 wks of gestation. These results were in agreement with Comestock et al., and Wong et al., study in sensitivity of $89 \%$ but in disagreement with these 2 studies in specifity of $50 \%$.

Regarding interruption of bladder line, in our study we found that it was specific at $32 \mathrm{wks}$ and 36 wks of gestation by $100 \%$ but more accurate at 36 wks by $43.33 \%$ and its sensitivity was about $22.73 \%$ at 36 wks of gestation.

These results were in agreement with Shawky et al., and Cali et al., in specify of $94 \%$ and sensitivity of $33 \%$. 14 Regarding the specificity $(100 \%)$ and PPV $=100 \%$, denoting the importance of this sign in diagnosis of placental accretion. According to placental lacunae sign, in our study we found that it was specific at 20 wks and 24 wks of gestation by $100 \%$, most sensitive at $36 \mathrm{wks}$ of gestation by $100 \%$ then at 32 wks by 95.45 $\%$ and more accurate at 28 wks by $80 \%$.In agreement of our study, Shawky et al., they found that Placental lacunae have a sensitivity of $89 \%$, specificity of $81 \%$, positive predictive value of $73 \%$ and negative predictive value of $93 \%$.
These results were also in agreement with a study by Wong et al., in sensitivity but in disagreement with specificity and positive predictive value of $39 \%$ and $17 \%$, respectively. And it was in agreement with study by Cali et al., in sensitivity of $73 \%$, specificity of $86 \%$, positive predictive value of $60 \%$ and negative predictive value of $90 \%$.

About tornado sign (turbulent flow), in our study we found that it was of specificity 100 $\%$ at 24,28 and 32 wks of gestation with PPV $(100 \%)$, it was most sensitive with $90.91 \%$ and most accurate with $86.67 \%$ at 36 wks. These results were in agreement with Comstock et al., and Shawky et al., studies who found that turbulent flow (Tornadoshaped flow of venous, arterial or mixed blood) are more likely with placenta accrete $(\mathrm{PPV}=100 \%)$.

About increased periuterine vascularity between uterus and urinary bladder, in our study we found that, it was most specific in $28,32,36$ wks of gestation by $100 \%$ and most accurate at 36 wks by $60 \%$ but its sensitivity was about $45.45 \%$ at 36 wks of gestation.

These results were in agreement with Cali et al., study in specificity of $100 \%$, but the sensitivity was $90 \%$ and this disagrees with our study.These results were in disagreement with Shawky et al., study as this sign sensitivity was $78 \%$ and specificity was $56 \%$.

It is concluded that the signs of diagnosis of placenta accreta by normal ultrasound and Doppler are sensitive and specific at different gestational ages, so early use of gray scale ultrasound and doppler is important in early diagnosis of placenta accreta. 
Table.1 Shows the operative end result of the cases whether conservative or hysterectomy

\begin{tabular}{|c|c|c|}
\hline \multicolumn{3}{|c|}{ Operative result } \\
\hline & N & $\%$ \\
\hline Conservative & 26 & 86.67 \\
\hline Hysterectomy & 4 & 13.33 \\
\hline Total & 30 & 100.00 \\
\hline
\end{tabular}

Table.2 Shows sensitivity and specificity of signs of placenta accrete that found in patients at different gestational age

\begin{tabular}{|c|c|c|c|c|c|c|c|c|c|c|}
\hline & \multicolumn{2}{|c|}{20 Weeks } & \multicolumn{2}{|c|}{24 Weeks } & \multicolumn{2}{|c|}{28 Weeks } & \multicolumn{2}{|c|}{32 Weeks } & \multicolumn{2}{|c|}{36 Weeks } \\
\hline & Sens. & Spec. & Sens. & Spec. & Sens. & Spec. & Sens. & Spec. & Sens. & Spec. \\
\hline $\begin{array}{c}\text { Thin } \\
\text { endometrium }\end{array}$ & 0 & 0 & 13.6 & 100.0 & 40.9 & 87.5 & 86.36 & 62.50 & 100.00 & 37.50 \\
\hline $\begin{array}{c}\text { Clear } \\
\text { retroplacental } \\
\text { space }\end{array}$ & 54.55 & 100.00 & 95.45 & 50.00 & 100.00 & 25.00 & 100.00 & 0.00 & 100.00 & 0.00 \\
\hline $\begin{array}{l}\text { Interruption } \\
\text { bladder line }\end{array}$ & 0.00 & 0.00 & 0.00 & 0.00 & 0.00 & 0.00 & 9.09 & 100.00 & 22.73 & 100.00 \\
\hline Lacunae & 18.18 & 100.00 & 63.64 & 100.00 & 86.36 & 62.50 & 95.45 & 12.50 & 100.00 & 0.00 \\
\hline Tornado sign & 30 & 100.00 & 4.55 & 100.00 & 18.18 & 100.00 & 68.18 & 100.00 & 90.91 & 75.00 \\
\hline $\begin{array}{l}\text { Increased } \\
\text { periuterine } \\
\text { Vascularity }\end{array}$ & 0.00 & 0.00 & 0.00 & 0.00 & 4.55 & 100.00 & 13.64 & 100.00 & 45.45 & 100.00 \\
\hline $\begin{array}{l}\text { Dilated vessels } \\
\text { around Cervix }\end{array}$ & 0.00 & 0.00 & 0.00 & 0.00 & 0.00 & 0.00 & 0.00 & 0.00 & 9.09 & 100.00 \\
\hline
\end{tabular}




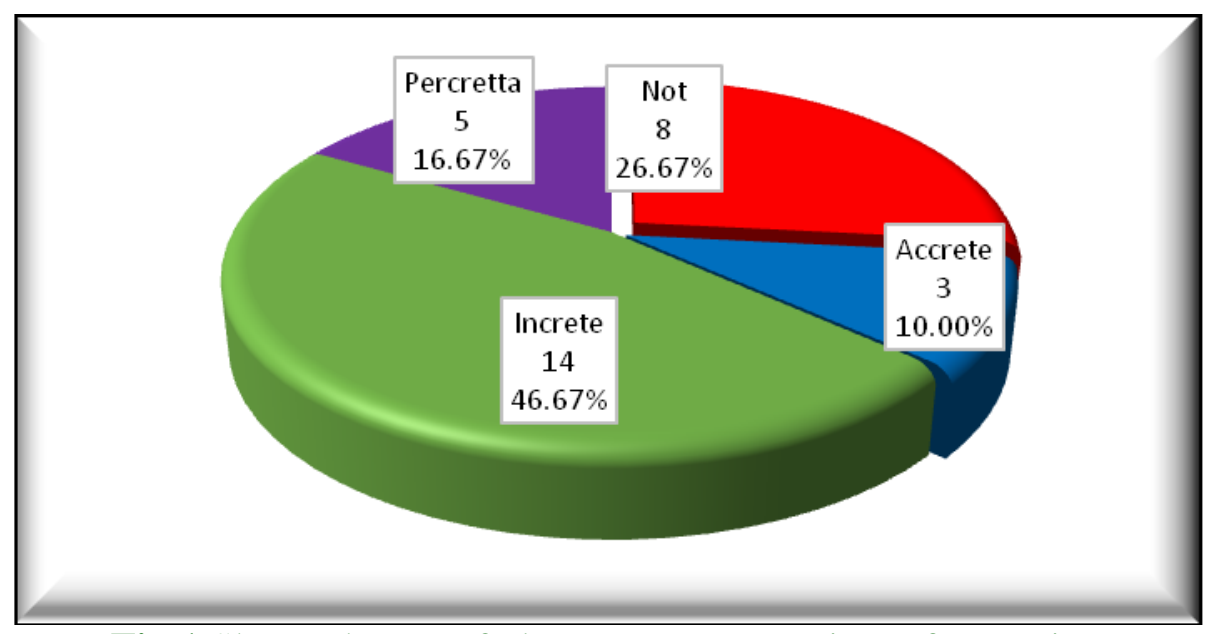

Fig.1 Shows degree of placenta accrete at time of operation

\section{References}

1. Baughman C, Cortevill J, Shad R. Placenta Accreta: Spectrum of US and Imaging Findings. Radio Graphics 2008; 28: $1905-1916$

2. Wu S, Kocherginsky M, Hibbard JU. Abnormal Placentation: twenty-year analysis. Am ObstetGynecol2005;192:1458-61.

3. Miller DA, CholletJA, Goodwin TM. Clinical risk factors for placenta previaplacenta accreta. Am J ObstetGynecol 1997; 177: 210-214.

4. Chou MM, Ho ES, Lee YH. Prenatal diagnosis of placenta previaaccreta by transabdominal color Doppler ultrasound. Ultrasound ObstetGynecol 2000; 15: 2835

5. Warshak CR, Eskander $\mathrm{R}$, Hull AD, Scioscia AL, Mattrey RF, Benirschke K, et al., Accuracy of ultrasonography and magnetic resonance imaging in the diagnosis of placenta accreta. ObstetGynecol2006;108:573-81

6. Shawky M, AbouBiehb E, Masood A. Gray scale and Doppler ultrasound in placenta accreta: Optimization of ultrasound signs. The Egyptian Journal of Radiology and Nuclear Medicine. 2016; 47: 1111-1115.

7. Chestnut DH, Dewan DM, Redick LF,
Caton D, Spielman FJ. Anesthetic management for obstetric hysterectomy: a multi-institutional study. Anesthesiology 1989;70:607-10

8. Comstock CH, Love JJ Jr, Bronsteen RA, Lee W, Vettraino IM, Huang RR, Lorenz RP. Sonographic detection of placenta accrete in the second and third trimesters of pregnancy. Am J ObstetGynecol 2004; 190: 1135-1140

9. Levine D, Hulka CA, Ludmir J, Li W, Edelman RR. Placenta accreta: evaluation with color Doppler US, power Doppler US, and MR imaging. Radiology 205: 773-776.

10. Comstock H. The antenatal diagnosis of placental attachment disorders. Curr Opin Obstet Gynecol 2011;23:117-22

11. Chou MM, Chen WC, Tseng JJ, Chen YF, Yeh TT, Ho ES. Prenatal detection of bladder wall involvement in invasive placentation with sequential two-dimensional and adjunctive three-dimensional ultrasonography. Taiwan J Obstet Gynecol 2009;48:38-45.

12. Mohamed Shawky, Essam AbouBieh, Alaa Masood.Gray scale and Doppler ultrasound in placenta accreta: Optimization of ultrasound signs.The Egyptian Journal of Radiology and Nuclear Medicine 2016;04.010

13. Wong HS, Ying KC, Zuccollo J, et al., 
Evaluation of sonographic diagnostic criteria for placenta accreta. J Clin Ultrasound 2008;36 (9):551-9.

14. Cali G, Giambanco L, Puccio G, et al., Morbidly adherent placenta: evaluation of

\begin{abstract}
ultrasound diagnostic criteria and differentiation of placenta accreta from percreta. Ultrasound Obstet Gynecol 2013;41:406-12.
\end{abstract}

\section{How to cite this article:}

Tala Abo Elnasr, Shereef Lotfy, Sameh Khodair and Karam Shaheen. 2020. Study of Different Gray Scale and Colour Doppler Ultrasonographic Findings for Diagnosis of Placenta Accreta. Int.J.Curr.Microbiol.App.Sci. 9(03): 1764-1771. doi: https://doi.org/10.20546/ijcmas.2020.903.204 